\title{
eGFR in CSF-flow disorders - a representation of comorbid state or an element of the underlying pathophysiology?
}

\author{
Patricia Haylock-Vize, Claudia Craven, Edward Dyson, Chari Aswin, Samir A Matloob, Andrew Stevens, \\ Simon D Thompson, Syed N Shah, Tarek Moustafa, Neekhil A Patel, Huan Wee Chan, Jinendra Ekanayake, \\ Ahmed K Toma, Laurence D Watkins
}

From Hydrocephalus 2015

Banff, Canada. 18-21 September 2015

\section{Introduction}

All cause mortality increases with lower levels of estimated glomerular filtration rates. As part of a comorbidity focus, we assessed the eGFR in CSF-flow disorder patients guided by NICE recommendations, current literature recognising a relative hazard ratio per $15 \mathrm{mls} / \mathrm{min}$ decrease in eGFR of 1.04[1] and consideration of the 2010 Chronic Kidney Disease Epidemiology Collaboration eGFR categories.

\section{Methods}

182 CSf-flow disorder patients who had eGFR measurement were grouped into the respective subtypes; IIH $(\mathrm{n}=41), \mathrm{NPH}(\mathrm{n}=72)$, CSF hypovolaemia $(\mathrm{n}=7)$ and other causes $(n=45)$. Others included those investigated for $\mathrm{NPH}$ but found not to be suitable for shunt.

Estimated GFR was categorised as per NICE guidelines; $(\mathrm{ml} / \mathrm{min} / 1.73 \mathrm{~m})$ in line with current clinical laboratory facilities;

$>90$ normal high,

60-89 mild reduction related to normal range for a young adult,

45-59 mild-moderate reduction,

30-44 moderate-severe reduction,

15-29 severe-reduction,

$<15$ kidney failure.

The eGFR's were recorded and the mean calculated for each subgroup.

\footnotetext{
* Correspondence: patriciahaylockvize@gmail.com

The National Hospital for Neurology and Neurosurgery, UK
}

\section{Results}

IIH cohort; mean eGFR 77.73;

26 patients $>90$ normal high, 14 patients in 60-80 mild reduction, and 1 patient 45-59 mild-moderate category.

Primary NPH; mean eGFR $73.32 \mathrm{mls} / \mathrm{min} ; 18$ patients $>90$ normal high, 35 patients $60-89$ mild reduction, 17 patients $45-59$ mild-moderate and 2 patients 30-44 moderate-severe category.

Secondary NPH; mean eGFR $81.94 \mathrm{mls} / \mathrm{min} ; 16$ patients 60-89 mild reduction range and 1 patient 45-59 mild-moderate category.

Orthostatic HA; mean eGFR $87.25 \mathrm{mls} / \mathrm{min}$; 5 patients $>90$ normal high and 2 patients $60-89$ mild reduction.

Other cohort; mean eGFR $76.96 \mathrm{mls} / \mathrm{min} ; 22$ patients $>90,21$ patients $60-89$ mild reduction and 2 patients 45-59 in the moderate-severe reduction.

Of the 182 patients, 71 patients had high normal eGFRs $>90 \mathrm{mls} / \mathrm{min}$ representing $39 \%$ of patients. $48 \%$ fell into the $60-89$ mild reduction range, $11.5 \%$ into the 45-59 mild-moderate reduction range and $1 \%$ into the moderate-severe reduction range.

\section{Conclusions}

A reduced estimated GFR is commonly seen in the CSFflow disorders patient cohorts. Given the emphasis towards comorbidity factors influencing surgical outcomes, this acts as a marker of comorbidity and physiological reserve for surgical tolerance and post-operative performance and should therefore be taken into consideration.

The altered eGFR could represent the comorbid state of the patient or it could form an element of the underlying pathophysiology of CSF-flow disorders or indeed

(C) 2015 Haylock-Vize et al. This is an Open Access article distributed under the terms of the Creative Commons Attribution License (http://creativecommons.org/licenses/by/4.0), which permits unrestricted use, distribution, and reproduction in any medium, provided the original work is properly cited. The Creative Commons Public Domain Dedication waiver (http://creativecommons.org/ publicdomain/zero/1.0/) applies to the data made available in this article, unless otherwise stated. 
both. Larger studies are required with more translational medical research models.

Published: 18 September 2015

\section{Reference}

1. Management of latrogenic Urinothorax following ultrasound guided percutaneous nephrostomy; Genitourinary Radiology 2014. Radiology Case 2014, 8(1):34-40, DOI: 10.3941/jrcr.v8i1.1424.

doi:10.1186/2045-8118-12-S1-P17

Cite this article as: Haylock-Vize et al.: eGFR in CSF-flow disorders - a representation of comorbid state or an element of the underlying pathophysiology? Fluids and Barriers of the CNS 2015 12(Suppl 1):P17.

Submit your next manuscript to BioMed Central and take full advantage of:

- Convenient online submission

- Thorough peer review

- No space constraints or color figure charges

- Immediate publication on acceptance

- Inclusion in PubMed, CAS, Scopus and Google Scholar

- Research which is freely available for redistribution

Submit your manuscript at www.biomedcentral.com/submit
C BioMed Central 